\title{
Editorial comment - the 50th volume of fungal diversity
}

\author{
(C) Kevin D. Hyde 2011
}

The 50th volume of Fungal Diversity contains a compilation of comprehensive reviews and critical articles on various hot topics in mycology. The papers span the period from when morphology was the basis for our understanding of most fungi until the present use of molecular data in classification and determination of species, showing the major changes taking place in mycology. The first paper from Aly et al. looks at 50 years of drug discovery and shows the importance of fungi in an age where these organisms are being used more often in drug discovery and medicine. Then there are important papers on the major groups of fungi and two other groups traditionally considered by mycologists, including myxomycetes (S.L. Stephenson), oomycetes (C.A. Lévesque), basidiomycetes (Z.L. Yang) and lichens (H.T.
Lumbsch and S.D. Leavitt), which examine developments from morphological studies to the molecular era. Two papers deal with ecological groups. E.B.G. Jones follows the progress in marine fungi over the past 50 years, while Ko Ko et al. explore the use of molecular data in identifying endophytes. The remaining papers deal with important pathogenic genera and show the major changes taking place in cryptic species recognition in these genera. L. Cai looks at the evolution of species concepts and species recognition criteria in plant pathogenic fungi. Specific genera dealt with include Fusarium (Summerell et al.), Mycosphaerella and Teratosphaeria (Hunter et al.), Pestalotiopsis (Maharachchikumbura et al.), Phomopsis (Udayanga et al.) and the rust Melampsora (Vialle et al.). 